\title{
Thyrostimulin, a heterodimer of two new human glycoprotein hormone subunits, activates the thyroid-stimulating hormone receptor
}

\author{
Koji Nakabayashi, ${ }^{1}$ Hirotaka Matsumi, ${ }^{1}$ Alka Bhalla, ${ }^{1}$ Jeehyeon Bae, ${ }^{1}$ Sietse Mosselman, ${ }^{2}$ \\ Sheau Yu Hsu, ${ }^{1}$ and Aaron J.W. Hsueh ${ }^{1}$ \\ ${ }^{1}$ Division of Reproductive Biology, Department of Gynecology and Obstetrics, Stanford University School of Medicine, \\ Stanford, California, USA \\ ${ }^{2}$ Department of Pharmacology, Organon Inc., Oss, The Netherlands
}

Address correspondence to: Aaron J.W. Hsueh, Department of Gynecology and Obstetrics, Stanford University School of Medicine, Stanford, California 94305-5317, USA.

Phone: (650) 725-6802; Fax: (650) 725-7102; E-mail: aaron.hsueh@stanford.edu.

Received for publication October 3, 2001, and accepted in revised form April 16, 2001.

\begin{abstract}
Human thyrotropin (TSH), luteotropin (LH), follitropin (FSH), and chorionic gonadotropin are members of the heterodimeric glycoprotein hormone family. The common $\alpha$ subunit forms noncovalent heterodimers with different $\beta$ subunits. Two novel human glycoprotein hormonelike genes, $\alpha 2$ (A2) and $\beta 5$ (B5), recently have been identified. Using a yeast two-hybrid assay, the two subunits were found as potential heterodimerization partners. Immunological analyses confirmed the heterodimerization of $\mathrm{A} 2$ and $\mathrm{B} 5$ in transfected cells and their colocalization in the anterior pituitary. Recombinant A2/B5 heterodimeric glycoproteins, purified using cation exchange and size fractionation chromatography, activated human TSH receptors, but not LH and FSH receptors, and showed high affinity to TSH receptors in a radioligand receptor assay. The heterodimer also stimulated cAMP production and thymidine incorporation by cultured thyroid cells and increased serum thyroxine levels in TSH-suppressed rats in vivo. This new heterodimeric glycoprotein hormone was named as thyrostimulin based on its thyroid-stimulating activity. The expression of thyrostimulin in the anterior pituitary known to express TSH receptors suggested a paracrine mechanism. The present discovery of a new ligand based on genomic approaches could facilitate the understanding of the physiological roles of extra-thyroid TSH receptor systems and the structural-functional basis of receptor signaling by related glycoprotein hormones.
\end{abstract}

J. Clin. Invest. 109:1445-1452 (2002). doi:10.1172/JCI200214340.

\section{Introduction}

Human thyrotropin (TSH), follitropin (FSH), lutropin $(\mathrm{LH})$, and chorionic gonadotropin (CG) are members of the glycoprotein hormone family derived from heterodimerization of a common $\alpha$ subunit with hormone-specific $\beta$ subunits. These hormones were originally purified from the anterior pituitary (TSH, LH, and FSH) and placenta (human CG) and shown to activate specific $G$ protein-coupled receptors in the thyroid (TSH receptor) and gonads (LH and FSH receptors), respectively (1-4). These three pituitary-derived glycoprotein hormones form the basis of the classic pituitary-peripheral target feedback systems and are essential for the development and differentiation of thyroid and gonadal tissues. In particular, TSH is essential for the production of iodothyronines by the thyroid gland and disorders of the pituitary-thyroid gland-thyroid hormone axis lead to disturbances of essentially all metabolic pathways and organs $(5,6)$.

Based on GenBank searches, we identified two additional human glycoprotein hormone subunitlike genes and named them $\alpha 2$ (A2) and $\beta 5$ (B5), due to their structural similarities to known subunits and the chronology of discovery (7). (The GenBank accession numbers for A2 and B5 are AF403384 and AF403430, respectively.) A2 and B5 have conserved cysteine residues, similar to those found in the well-characterized $\alpha$ and $\beta$ subunits $(8,9)$ important for the formation of key disulfide bonds. Like all other glycoprotein hormone subunits, $\mathrm{A} 2$ and $\mathrm{B} 5$ have the unique cystine knot structure characteristic of proteins related to the TGF- $\beta$, the PDGF, and the bone morphogenetic protein families $(10,11)$. Because the putative $\mathrm{A} 2$ subunit is likely to combine with either known or novel $\beta$ subunits to yield bioactive heterodimeric hormones, we performed a yeast two-hybrid protein-protein interaction screen to identify potential dimerization partners for $\mathrm{A} 2$ and found interactions between $\mathrm{A} 2$ and $\mathrm{B} 5$. We generated $A b$ 's against $A 2$ and $B 5$ to confirm the interactions between these putative subunits and their colocalization in the anterior pituitary. Following testing for the activation of glycoprotein hormone receptors, 
the A2/B5 heterodimer was found to stimulate TSH but not gonadotropin receptors in vitro and in vivo. The present approach provides a new paradigm for discovering low-abundance heterodimeric polypeptide ligands using bioinformatic, yeast two-hybrid, and ligand-receptor matching approaches.

\section{Methods}

Yeast two-bybrid testing and RT-PCR analyses. Interactions between $\mathrm{A} 2$ and different glycoprotein hormone subunits were assessed in the yeast two-hybrid system using pGBT9 GAL4-binding domain (BD) and PGADGH GAL4-activation domain (AD) vectors (12). Specific binding of different protein pairs was evaluated based on the activation of GAL1-HIS3 and GAL4-lacZ reporter genes (Clontech Laboratories Inc., Palo Alto, California, USA). The mature region of human $\mathrm{A} 2 \mathrm{cDNA}$ was fused to the GAL4-AD in a yeast shuttle vector, pGADGH. Similarly, cDNAs encoding other glycoprotein hormone subunits without the signal peptides were fused to the GAL-4-BD of the pGBT9 vector. Specific interactions of different protein pairs were evaluated based on the activation of the GAL1-HIS3 reporter gene in medium lacking leucine, tryptophan, and histidine but in the presence of $5 \mathrm{mM}$ 3-aminotriazole (13). At least 10 different colonies expressing each pair of fusion proteins were tested.

For RT-PCR analysis of A2 and B5 mRNA expression, tissues were collected from 50-day-old Sprague-Dawley male rats (Simonsen Laboratories Inc., Gilroy, California, USA). Total mRNA was extracted using TRIzol reagent (Life Technologies Inc., Grand Island, New York, USA) before RT to obtain cDNAs. PCR amplification of cDNA was carried out under high-stringency conditions (denaturation: $94^{\circ} \mathrm{C}, 30$ seconds; annealing and extension: $68-72^{\circ} \mathrm{C}, 3$ minutes, 35 cycles). The specific primers are: A2 upstream primer, CATCCCAGGCTGCCACTTGCACCCCTTC; A2 downstream primer, CTTTCTGAGGCTGCTGATGGTGCAGC; B5 upstream primer, ATGGCCCTCCTCCTTCTGGCTGGCTAT; B5 downstream primer, CTCCGCAGTCACAGCGGATGGCCACGG. Omission of the RT step led to loss of the PCR products.

Generation of $A b$ 's to $A 2$ and $B 5$ and immunoanalyses. For $\mathrm{Ab}$ production, $\mathrm{cDNAs}$ corresponding to the mature region of human $\mathrm{A} 2$ or $\mathrm{B} 5$ were subcloned into the PGEX-4T-1 vector (Amersham Pharmacia Biotech, Piscataway, New Jersey, USA). After transformation into the Escherichia coli strain BL21 (Invitrogen Corp., Carlsbad, California, USA), expression of fusion proteins consisting of glutathione S-transferase and mature A2 or B5 was induced following treatment with isopropyl1 -thio- $\beta$-D-galactoside. Fusion proteins in the bacterial lysate were purified using a glutathione-Sepharose 4B-affinity column, emulsified in Freund's adjuvant, and injected into rabbits (Strategic BioSolutions Inc., Newark, Delaware, USA) for Ab generation. IgG was purified using the Protein G Sepharose 4 Fast Flow column (Amersham Pharmacia Biotech).

For the production of A2/B5 dimers, human fetal kidney $293 \mathrm{~T}$ cells were transfected with A2 and B5 subunit
cDNAs subcloned into a bipromoter $\mathrm{pBudCE} 4.1$ vector (Invitrogen Corp.) using the calcium phosphate precipitation method. Serum-free conditioned media containing recombinant proteins were collected and concentrated 200 -fold using Ultrafree $10-\mathrm{kb}$ membranes. The media were boiled in SDS sample buffer for 5 minutes and subjected to $12 \%$ Tricine-SDS-PAGE. For immunoblotting, the membrane was blocked in $5 \%$ nonfat dry milk in Tris-buffer saline with $0.1 \%$ Tween 20 for 1 hour, followed by incubation with anti-rabbit A2 or B5 polyclonal $\mathrm{Ab}$ for 1 hour at room temperature. The blot was then incubated for 30 minutes with $0.1 \mu \mathrm{g} / \mathrm{ml}$ of anti-rabbit IgG-horseradish peroxidase conjugate (Promega Corp., Madison, Wisconsin, USA) as a secondary Ab before visualization by enhanced chemiluminescence (Amersham Pharmacia Biotech). Similar immunoblotting tests were also performed using extracts of anterior pituitary obtained from adult male rats.

For immunostaining, anterior pituitary from adult male rats was embedded in paraffin after fixation in Bouin's solution. Tissue sections were blocked with 5\% goat serum in PBS for 30 minutes to saturate nonspecific binding sites. The primary rabbit polyclonal $\mathrm{Ab}$ to A2 or B5 was diluted to 1:200 in PBS containing 5\% goat serum. Sections were incubated overnight at $4^{\circ} \mathrm{C}$ and washed three times for 20 minutes each in PBS. Sections were then incubated with gold-conjugated goat antirabbit secondary $\mathrm{Ab}$ followed by staining with SilvEnhance solution (Zymed Laboratories Inc., South San Francisco, California, USA) as described previously (14). Negative controls were performed by substituting the primary $\mathrm{Ab}$ with rabbit preimmune serum.

For immunohistochemical analysis using fluorescent double labeling (15), fixed sections were incubated with the B5 Ab followed by the fluorescein-conjugated AffiniPure Fab fragment of goat anti-rabbit IgG (Jackson ImmunoResearch Laboratories Inc., West Grove, Pennsylvania, USA). Subsequently, the sections were incubated with the $\mathrm{A} 2 \mathrm{Ab}$ followed by Texas red dyeconjugated AffiniPure goat anti-rabbit intact IgG. Fluorescence of fluorescein was observed at an excitation wavelength of $495 \mathrm{~nm}$ and an emission of more than $515 \mathrm{~nm}$. Fluorescence of Texas red was observed at an excitation of $510 \mathrm{~nm}$ and an emission of more than 580 $\mathrm{nm}$. In some tests, the $\mathrm{B} 5 \mathrm{Ab}$ was replaced with $\mathrm{Ab}$ against individual known pituitary hormones provided by the National Pituitary and Hormone Distribution program (NIH, Bethesda, Maryland, USA).

Purification of the A2/B5 heterodimer using fast protein liquid chromatography and stimulation of human TSH receptors. Conditioned media from $293 \mathrm{~T}$ cells expressing both A2 and B5 were applied to Ultrafree concentrators with a molecular mass cutoff between 10 and $100 \mathrm{kDa}$ (Millipore Corp., Bedford, Massachusetts, USA). The supernatant was applied to a Mono S HR10/10 (Amersham Pharmacia Biotech) cation exchange column at $4^{\circ} \mathrm{C}(20$ $\mathrm{mM}$ 2-[N-morpholino] ethanesulfonic acid, $\mathrm{pH}$ 6.6), and peak fractions were used for immunoblotting to detect fractions with both $\mathrm{A} 2$ and $\mathrm{B} 5$ antigenicity. Pos- 
itive fractions were then dialyzed against PBS and concentrated before application onto a Superdex G75 column for size fractionation and bioactivity determination. The purity of the A2/B5 heterodimer was confirmed by silver staining following SDS-PAGE, and the quantitation of purified $\mathrm{A} 2 / \mathrm{B} 5$ was based on the Bradford assay (BioRad Laboratories Inc., Hercules, California, USA). Due to instability of the A2/B5 dimer during SDS-PAGE, dimer formation was verified using cross-linking analysis. Purified complexes of $\mathrm{B} 5$ and A2 were cross-linked using $1 \mathrm{mM}$ disuccinimidyl suberate (DSS) (Pierce Chemical Co., Rockford, Illinois, USA) for 30 minutes, and the reaction was terminated by the addition of $1 \mathrm{M}$ Tris-HCl, $\mathrm{pH}$ 7.4. Cross-linked complexes were monitored using SDS-PAGE $(10 \%)$ under reduced conditions. The glycoprotein nature of A2/B5 was confirmed by treating purified heterodimers with $\mathrm{N}$-glycosidase F (New England Biolabs Inc., Beverly, Massachusetts, USA) before SDS-PAGE.

Assessment of thyroid-stimulating activity in vitro and in vivo. The 293T cells were transfected with plasmids encoding human TSH, LH, or FSH receptor cDNAs $(16,17)$ and incubated in DMEM/F12 medium supplemented with $1 \mathrm{mg} / \mathrm{ml}$ of BSA and $0.25 \mathrm{mM}$ IBMX with or without A2/B5, bovine TSH, human TSH (Genzyme Transgenics Corp., Framingham, Massachusetts, USA), or gonadotropins. At 16 hours after incubation, cAMP production was determined using a specific radioimmunoassay (18). To demonstrate the specificity of the stimulatory effects of A2/B5, samples were preincubated with antisera against $\mathrm{A} 2$ or $\mathrm{B} 5$, or preimmune serum, for 1 hour before addition to the cultured cells. For radioligand receptor assays, bovine TSH was labeled using Iodogen (Pierce Chemical Co.). The 293T cells stably expressing wild-type human TSH receptors were incubated with $I^{125}$-labeled TSH $(10,000 \mathrm{cpm} /$ tube $)$ with or without unlabeled TSH or A2/B5 in $300 \mu 1$ binding buffer (HBSS; $280 \mathrm{mM}$ sucrose and 0.5\% BSA). After incubation for 3 hours at $23^{\circ} \mathrm{C}$, cells were washed twice and centrifuged before counting radioactivity in the pellet using a gamma counter.

The ability of A2/B5 to regulate thyroid functions was tested using in vitro (19) and in vivo (20) assays. Clonal rat thyroid FRTL5 cells were maintained in Coon's modified Ham's F12 medium containing 5\% calf serum before treatment with test hormones for 16 hours for the measurement of cAMP content using a specific radioimmunoassay. Assays for ${ }^{3} \mathrm{H}$-thymidine incorporation were performed on subconfluent monolayers of FRTL 5 cells. Four days before the assay, media were changed to serum-free media containing $0.1 \%$ BSA. Cells were then treated with test hormones for 20 hours before adding ${ }^{3} \mathrm{H}$-thymidine. After 4 hours of incubation, cells were washed twice with buffer and three times with ice-cold trichloroacetic acid. The precipitate was then solubilized in $500 \mu \mathrm{l}$ of $0.2 \mathrm{M} \mathrm{NaOH}$ and neutralized with $50 \mu \mathrm{l}$ glacial acetic acid before the measurement of radioactivity. For the in vivo TSH bioassay, 50-day-old male rats were given triiodothyronine $(3 \mu \mathrm{g} / \mathrm{ml})$ in their drinking water for 4 days $(20)$, to suppress endogenous TSH secretion. Increasing doses of recombinant $\mathrm{A} 2 / \mathrm{B} 5$ or bovine TSH were injected intraperitoneally, and blood samples were obtained 6 hours later. Serum thyroxine (T4) levels measured by radioimmunoassay (Diagnostic Systems Laboratories Inc., Webster, Texas, USA) served as the assay endpoint.

\section{Results}

The sequences of human B5 and A2 were compared with human TSH- $\beta$ and the common $\alpha$ subunit, respectively (Figure 1a). Although the B5 sequence lacks the C-terminal "seat belt" region, all cysteine residues needed for cystine knot formation are conserved. Because the newly identified $\alpha$ subunit A2 like- a $\begin{array}{rrrr}\text { A } & 1 & \text { MKLAFLFLGPMALLLLAGYGCVLGASSGNLRTFVGCAVREFTFLAKKPGC-R } \\ \text { TSH } \beta & 1 & \text { MTALFLMSMLFGLACGQAMSFCIPTEYTMHIERRECAY } \\ \text { B5 } & 52 & \text { GLRITTDACWGRCETWEKPILEPPY IEAHHR-VCTYNETKQVTVKLPNCAPG } \\ \text { TSH } \beta & 39 & \text { CLTINTTICAGYCMTRDINGKLFLPKYALSQDVCTYRDFIYRTVEIPGCPLH } \\ \text { B5 } & 103 & \text { VDPFYTYPVAIRCDCGACSTATTECETI } & 130 \\ \text { TSH } \beta & 91 & \text { VAPYFSYPVALSCKCGKCNTDYSDCIHEAIKTNYCTKPQKSYLVGFSV } & 138\end{array}$

A 1 MDYYRKYAAIFLVTLSVFLHVLHSAPDVODCPECTLQENPFFSOPGA A2 1 MPMASPQTLVLYLLVIAVTEAWGQEAVIPGCHLHPFNVTVRSDRQGTCQGSH

A 48 PILQCMGCCFSRAYPTPLRSKKTMLVQKNVTSESTCCVAK---------SYNR

A2 53 VAQACVGHCESSAFPSRYSVLVASGYRHNITSVSQCCTISGLKKVKVQLQCV

A 92 VTVMGGFKVENHTACHCSTCYYHKS

A2 105 GSRREELEIFTARACQCDMCRLSRY

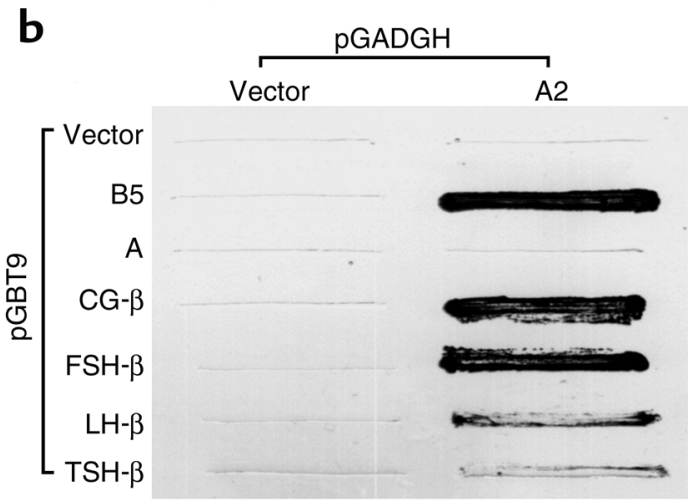

\section{Figure 1}

Identification of $\mathrm{A} 2$ and $\mathrm{B} 5$ as potential heterodimerization partners. (a) Comparison of sequences between human B5 and TSH- $\beta$ as well as $A 2$ and the common $\alpha$ subunit (A). (b) Yeast two-hybrid analyses of interactions between A2 and different subunit genes in the glycoprotein hormone family. Yeast cells were transfected with plasmids encoding A2, and different subunit genes fused to the GAL4 activation domain and the binding domain, respectively. The prominent growth of colonies expressing A2 and B5 indicates a strong interaction between these proteins. Interactions between A2 and CG- $\beta$, as well as A2 and FSH- $\beta$, were also observed, whereas no growth of yeast colonies was found in cells expressing only $\mathrm{A} 2$, thus ruling out self-activation of these constructs. 
a

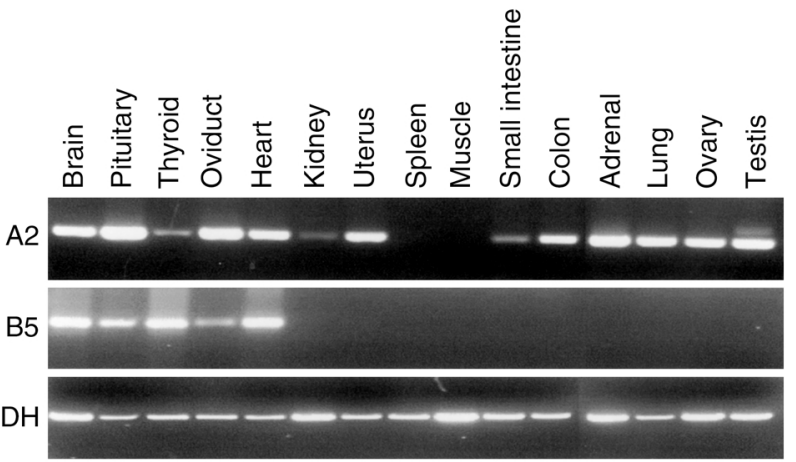

b

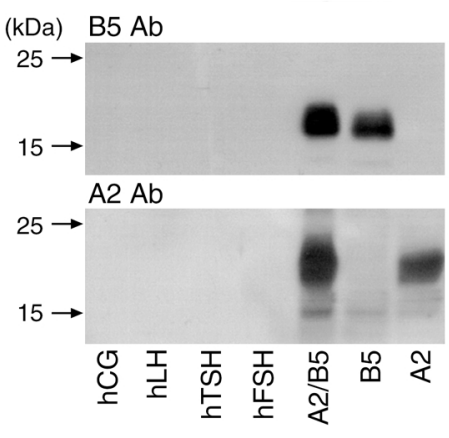

C

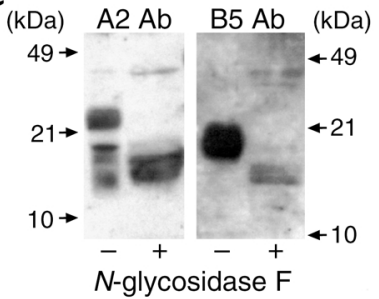

d

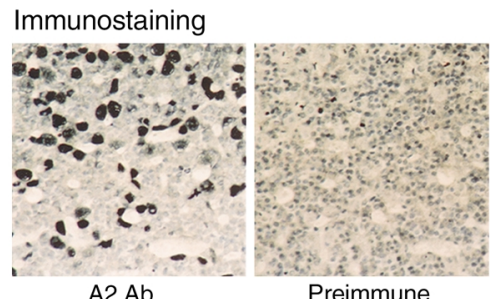

$\mathrm{A} 2 \mathrm{Ab}$

Preimmune

Immunofluorescence

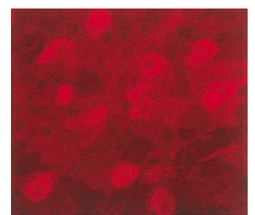

$\mathrm{A} 2 \mathrm{Ab}$

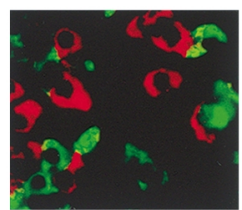

$A 2 A b+G H A b$

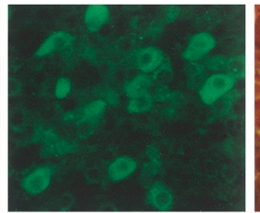

B5 Ab

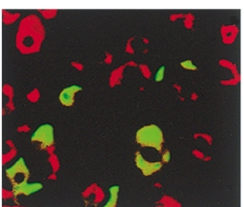

$A 2 A b+P R L A b$

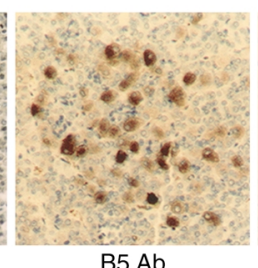

B5 Ab

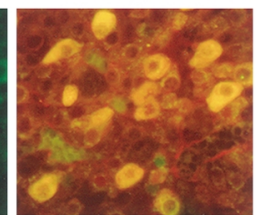

$A 2 A b+B 5 A b$

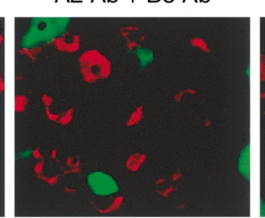

$A 2 A b+L H \beta A b$

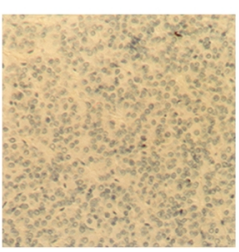

Preimmune

\section{Figure 2}

Expression of $\mathrm{A} 2$ and $\mathrm{B} 5 \mathrm{mRNA}$ in rat tissues and immunoanalyses of $A 2$ and $B 5$ in the anterior pituitary. (a) RT-PCR analysis of A2 and B5 transcripts in rat tissues. Amplification of the GAPDH message levels reflected differences in cDNA loading. (b) Hormonal specificity of Ab's against A2 and B5. Immunoblotting analysis indicated that Ab's against A2 or B5 recognized proteins secreted by 293 T cells transfected with expression plasmids encoding $\mathrm{A} 2$ or $\mathrm{B} 5$, or $\mathrm{A} 2$ and $\mathrm{B} 5$. However, no signal could be found in lanes loaded with $500 \mathrm{ng}$ of recombinant human (h) CG, LH, FSH, or TSH. A lower band in the A2 immunoblot was found to be nonspecific. (c) Immunoblot analysis of A2 and B5 in the rat anterior pituitary. Pituitary extracts were used for analysis. Some samples were pretreated with $\mathrm{N}$-glycosidase $\mathrm{F}$. (d) Immunostaining of $A 2$ and $B 5$. Anterior pituitary showed positive staining using $A 2$ or B5 Ab's (upper panel), whereas the preimmune serum was ineffective. Double-fluorescent immunostaining was performed using a B5 Ab followed by the fluorescein-conjugated AffiniPure Fab fragment goat anti-rabbit IgG (middle panel). Subsequently, the same section was incubated with the A2 $A b$ followed by Texas red dye-conjugated AffiniPure goat anti-rabbit intact IgG. The images for A2 (red) and B5 (green) were merged (yellow) to demonstrate the coexpression of these two subunits. As a negative control, omission of the A2 Ab did not lead to signals derived from the Texas red dye (data not shown). Using the double-immunostaining approach, a lack of coexpression was found between $\mathrm{A} 2$ (red) and $\mathrm{ACTH}$, growth hormone $(\mathrm{GH})$, prolactin (PRL), LH $\beta$, or $\mathrm{TSH}-\beta$ (all in green; middle and lower panels). ly combines with either known or novel $\beta$ subunits to form bioactive heterodimeric hormones, we tested potential interactions between different pairs of the subunit genes by using a yeast two-hybrid assay. As shown in Figure $1 \mathrm{~b}$, strong interactions were found between the A2 subunit and B5, CG- $\beta$, or FSH- $\beta$. However, minimal interactions were found between $\mathrm{A} 2$ and LH- $\beta$ or TSH- $\beta$. Based on these findings, we constructed dual promoter plasmids encoding different pairs of subunits and tested their potential activation of human gonadotropin and TSH receptors. It is of interest that the conditioned media of 293T cells transfected with cDNAs encoding the A2/B5 pair was capable of stimulating cAMP production by cells expressing TSH receptors (see Figure 3 and Figure 4, described below).

To detect the expression of $\mathrm{A} 2$ and $\mathrm{B} 5$ in diverse tissues, RT-PCR analysis was performed to identify rat tissues expressing both A2 and B5. As shown in Figure 2a, the A2 transcript consistent with an expected size of 208 bp could be detected in diverse tissues, whereas the B5 message with an expected size of $346 \mathrm{bp}$ was found only in brain, anterior pituitary, thyroid, oviduct, and heart. The primers used were not intron spanning, and the identity of the PCR products was confirmed by direct sequencing. Omission of mRNA in the RT-PCR reaction yielded no product. 
We then generated specific Ab's against A2 and B5 to detect the expression of these proteins. In immunoblots under reducing conditions (Figure $2 \mathrm{~b}$ ), specific $\mathrm{A} 2$ and B5 Ab's did not cross-react with the four known glycoprotein hormones but detected bands of approximately 23 and $20 \mathrm{kDa}$ in the conditioned media of transfected cells, corresponding to the $\mathrm{A} 2$ and $\mathrm{B} 5$ subunits, respectively. An initial survey of tissues expressing both $\mathrm{A} 2$ and B5 transcripts indicated that the anterior pituitary had high levels of immunoreactivity, whereas brain, thyroid, and ovary did not exhibit both antigens in the same cell type. As shown in Figure 2c, both A2 and B5 immunoreactivities could be detected in the rat anterior pituitary using immunoblot analysis. Major bands of 23 and 20 $\mathrm{kDa}$ were found for $\mathrm{A} 2$ and $\mathrm{B} 5$, respectively. Upon treatment with $\mathrm{N}$-glycosidase F, lower mol wt bands were detected, consistent with the glycoprotein nature of these subunit proteins. We further performed immunohistochemical staining of A2 and B5. As shown in Figure $2 \mathrm{~d}$ (upper panel), both A2 and B5 immunoreactivities were found in the rat anterior pituitary. To verify the coexpression of the A2 and B5 subunits, double-fluorescent immunostaining was performed. As shown in Figure $2 \mathrm{~d}$ (middle panel), multiple cells expressed both $\mathrm{A} 2$ and B5 antigens in the anterior pituitary. Although the specific cell type coexpressing A2 and B5 has not been identified, the A2-positive cells did not show costaining with $\mathrm{ACTH}$, growth hormone, prolactin LH- $\beta$, or TSH- $\beta$ (Figure $2 \mathrm{~d}$, middle and lower panels).

To further analyze the biochemical nature and bioactivity of the recombinant A2/B5 proteins, conditioned media from 293T cells expressing the A2/B5 heterodimer were passed through a Mono-S cation exchange column. As shown in Figure 3a, a major peak of protein was eluted between $30-35 \% 1 \mathrm{M} \mathrm{NaCl}$. These fractions contained high levels of A2 and B5 subunits in immunoblots (upper panel) and exhibited TSH receptor-stimulating activity (data not shown). In contrast, fractions 1 and 55 did not contain detectable A2 or B5 subunits. The peak fractions (fractions 30-38) were concentrated and passed through a Superdex G-75 size fractionation column before bioactivity monitoring based on the stimulation of cAMP production by 293T cells expressing human TSH receptors (Figure 3b, dashed line). Again, the peak of TSH receptor-stimulating activity coincided with fractions containing both $\mathrm{A} 2$ and $\mathrm{B} 5$ bands in immunoblots (Figure 3b, upper left panel). The mol wt of the bioactive proteins in these fractions was estimated to be $43 \mathrm{kDa}$ based on mol wt markers. Silver staining of pooled peak fractions following SDS-PAGE further indicated the purification of a complex composed of A2 and B5 subunits (Figure 3b, upper right panel). Based on its thyroid-
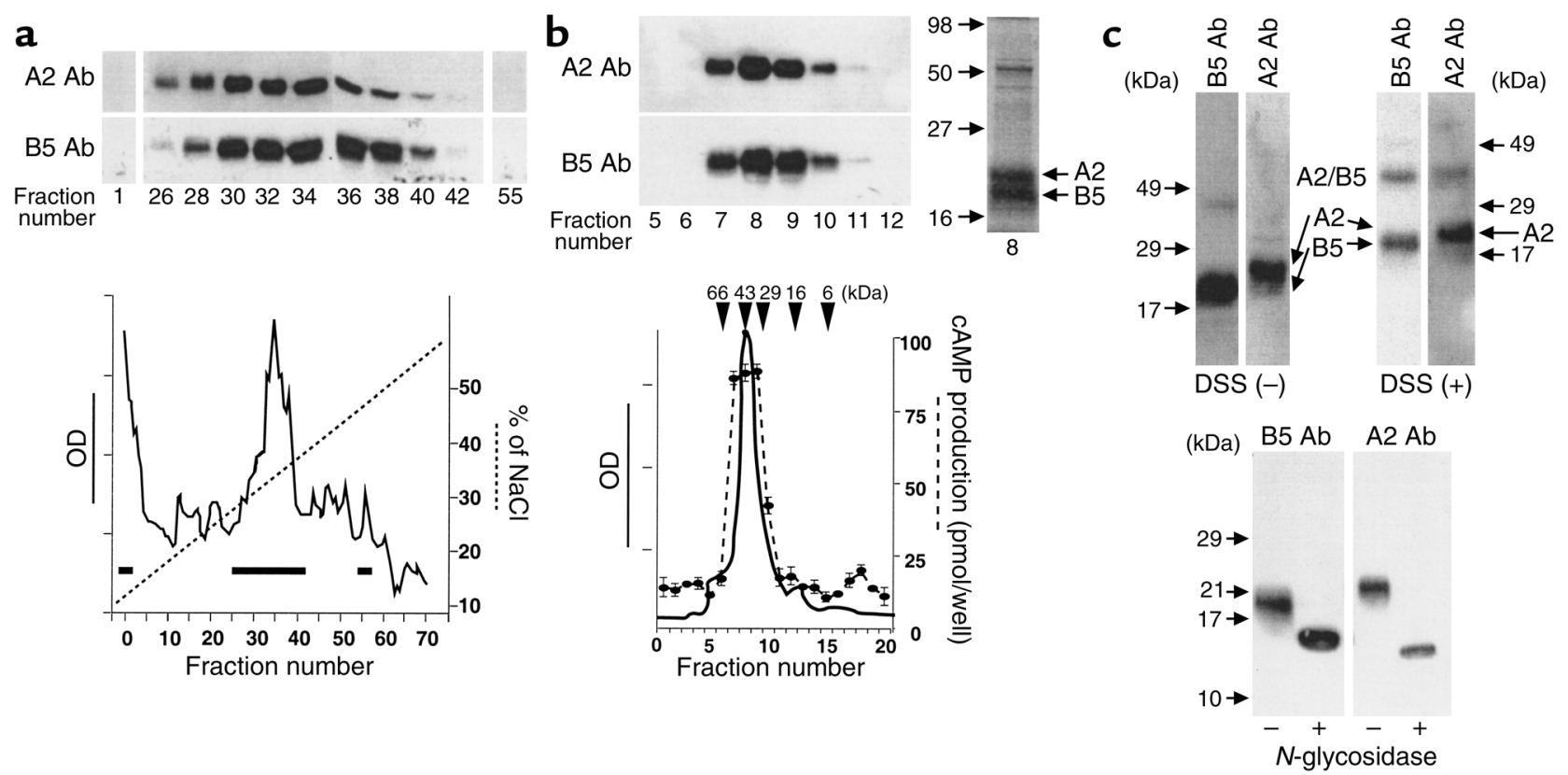

Figure 3

Purification of the A2/B5 heterodimer and characterization of its glycoprotein nature. (a) Isolation of A2/B5 using the Mono-S cation exchange column. Conditioned media from 293T cells expressing A2/B5 heterodimers were concentrated before fractionation using the Mono-S column. Samples were eluted using a $\mathrm{NaCl}$ gradient. Immunoreactive A2 and B5 were monitored using immunoblots (upper panel) in selected fractions (lower panel, thick bars). (b) Further purification of the A2/B5 dimer using the Superdex G-75 column and its stimulation of TSH receptors. Peak fractions from the Mono-S column were further analyzed using the Superdex sizing column. TSH receptor-stimulating activity was monitored based on cAMP production by cells expressing recombinant human TSH receptors (dashed line). A2 and B5 levels in the peak fractions were monitored by immunoblots (upper left panel) and silver staining (upper right panel). (c) Heterodimerization of recombinant A2/B5 based on cross-linking analysis and the glycoprotein nature of the A2/B5 heterodimer. Peak fractions of the Superdex column containing purified B5 and A2 were cross-linked using 1 mM DSS (upper right panel) or treated with N-glycosidase $F$ (bottom panel) before SDS-PAGE and immunoblotting under denaturing conditions. The upper left panel shows samples without pretreatment with DSS. 
a

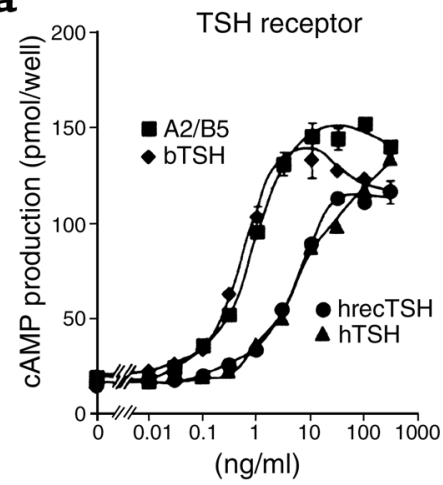

b

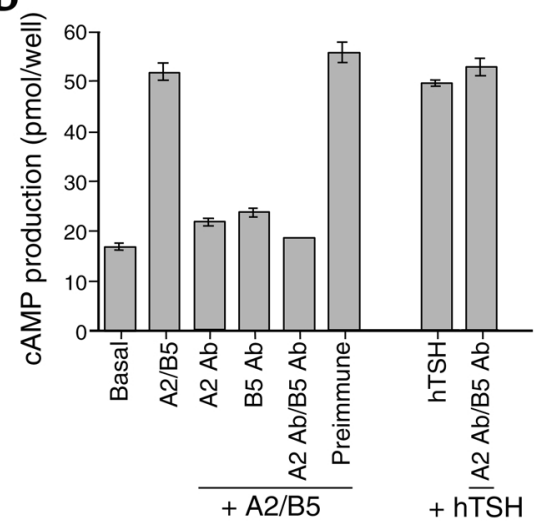

d

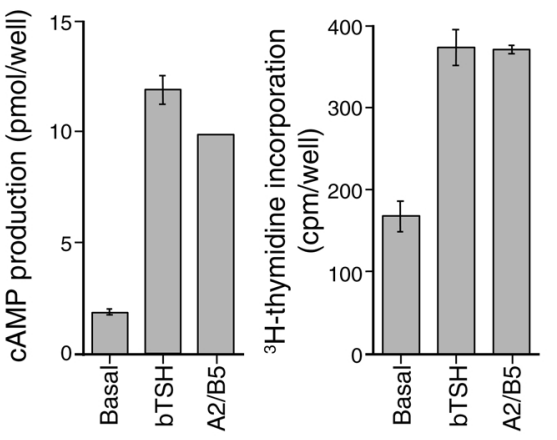

LH receptor FSH receptor
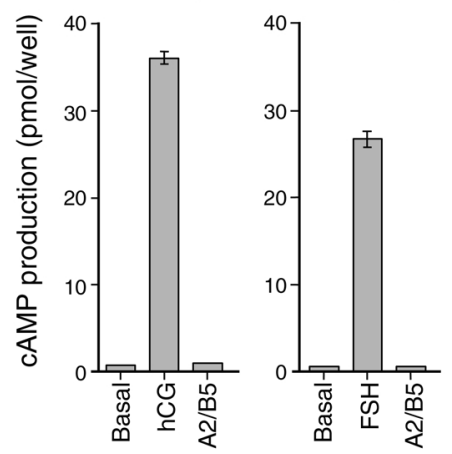

C

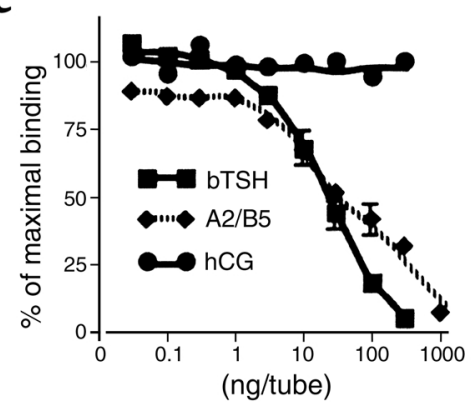

Figure 4

Thyroid-stimulating activity of the purified A2/B5 heterodimer. (a) Purified A2/B5, like $\mathrm{TSH}$, stimulated cAMP production mediated by human TSH receptors, but not by $\mathrm{LH}$ and FSH receptors. Dose-dependent effects of A2/B5 and other hormones (left panel). b, bovine; hrec, human recombinant; h, human. Lack of stimulation of $\mathrm{LH}$ and $\mathrm{FSH}$ receptors by $\mathrm{A} 2 / \mathrm{B} 5$ (right panel). Human CG or FSH (100 ng/ml) were used to serve as positive controls (right panel). (b) Ability of specific A2 or B5 Ab's (1:100 dilution) to neutralize the stimulatory effect of A2/B5 $(0.3 \mathrm{ng} / \mathrm{ml})$ on cAMP production mediated by TSH receptors. Addition of preimmune serum did not alter the stimulatory effects of A2/B5. In addition, pretreatment with $\mathrm{A} 2$ and $\mathrm{B} 5$ antisera did not affect CAMP production induced by human TSH $(3 \mathrm{ng} / \mathrm{ml})$. (c) Displacement of labeled bovine TSH from the recombinant human $\mathrm{TSH}$ receptors by $\mathrm{A} 2 / \mathrm{B} 5$. Human CG was included as a negative control. (d) Purified A2/B5 (100 ng/ml) promoted cAMP production and thymidine incorporation by cultured rat thyroid FRTL5 cells in vitro. bTSH, bovine TSH $(100 \mathrm{ng} / \mathrm{ml}$ ). (e) A2/B5 induction of $\mathrm{T} 4$ production by the thyroid gland in mice pretreated with triiodothyronine (T3) to suppress endogenous TSH levels. Each data point represents the mean $\pm \mathrm{SE}$ of three to four determinations with similar results obtained in at least three separate experiments.

stimulating property, this purified heterodimeric protein was named thyrostimulin to distinguish it from the known thyroid-stimulating hormone, TSH.

Although thyrostimulin subunits dissociated under nonreducing SDS-PAGE (data not shown), we detected the presence of high mol wt complexes corresponding to the size of the predicted heterodimer after cross-linking of the purified A2/B5 protein (Figure 3c, upper right panel). The glycoprotein nature of thyrostimulin was further tested by treating the purified heterodimer with $\mathrm{N}$-glycosidase $\mathrm{F}$ followed by immunoblotting. As shown in Figure 3c (bottom panel), observed decreases in the size of $\mathrm{A} 2$ and $\mathrm{B} 5$ subunits are consistent with the presence of $N$-linked glycosylation sites in these peptides (Asn 14 and 58 in A2; Asn 63 in B5).

In cells expressing recombinant human TSH receptors, purified thyrostimulin was found to be as potent as bovine TSH and more potent than human TSH in stimulating cAMP production (Figure 4a, left panel). The $\mathrm{ED}_{50}$ values for $\mathrm{A} 2 / \mathrm{B} 5$ and bovine $\mathrm{TSH}$ were 0.72 and $0.44 \mathrm{ng} / \mathrm{ml}$, respectively. In contrast, the $\mathrm{ED}_{50} \mathrm{val}-$ ues for human recombinant and pituitary TSH preparations were 4.05 and $6.26 \mathrm{ng} / \mathrm{ml}$, respectively. However, thyrostimulin was ineffective in activating either $\mathrm{LH}$ or FSH receptors (Figure 4a, right panels). Furthermore, the stimulatory effects of thyrostimulin were blocked by cotreatment with either A2 or B5 antisera or both (Figure $4 \mathrm{~b}$ ). In a radioligand receptor assay based on labeled bovine TSH and recombinant human TSH receptors (Figure 4c), thyrostimulin competed efficiently for receptor binding with an $\mathrm{ED}_{50}$ value $(32.5 \mathrm{ng} /$ tube $)$ comparable to that of bovine TSH ( $28.5 \mathrm{ng} / \mathrm{tube})$. Furthermore, treatment of a rat thyroid FRTL5 cell line with thyrostimulin, similar to bovine TSH, stimulated cAMP production and thymidine incorporation (Figure $4 \mathrm{~d}$ ), thus confirming the activation of TSH receptors by 
thyrostimulin. To test the thyroid-stimulating activity of thyrostimulin in vivo, adult male rats were treated with triiodothyronine to suppress the endogenous TSH secretion followed by subcutaneous treatment with thyrostimulin. As shown in Figure 4e, treatment with thyrostimulin is more potent than bovine TSH in increasing $\mathrm{T} 4$ levels, thus demonstrating its bioactivity in vivo.

\section{Discussion}

Based on the dimerization of two new glycoprotein hormone subunits, we have identified a novel heterodimeric glycoprotein hormone capable of activating TSH receptors in vitro and in vivo. Due to its ability to stimulate thyrotropin receptors, this hormone was named thyrostimulin. The expression of this glycoprotein hormone and TSH receptors in the anterior pituitary suggests a paracrine-signaling mechanism. The present use of GenBank searches, yeast two-hybrid testing, tissue expression analysis, and the production and testing of recombinant heterodimers represents a postgenomic paradigm in polypeptide hormone discovery. The classic heterodimeric thyrotropin and gonadotropins were originally purified based on their bioactivity, but the present approach takes advantage of the phylogenetic relationship among known and novel paralogous subunit genes, the characterized heterodimeric nature of glycoprotein hormones, and the known signaling mechanisms of thyrotropin and gonadotropin receptors.

Although thyrostimulin was found to be a potent stimulator of thyroid cell functions in vitro and in vivo, its exact role in thyroid physiology is still unknown. TSH- $\beta$ loss-of-function mutations have been found in patients with congenital central hypothyroidism (21-24). Because these patients exhibited defective thyroid functions, it is unlikely that thyrostimulin participates in the TRH-TSH-T4 feedback loop to substitute the thyroid action of TSH in adult life. Indeed, promoter analysis indicated that the human B5 gene lacks a thyroid response element and may not be regulated by thyroid hormones. More likely, thyrostimulin may play a paracrine role in the anterior pituitary and other tissues expressing TSH receptors. In addition to thyroid cells, expression of the TSH receptor has been demonstrated in the folliculo-stellate cells and thyrotrophs of human anterior pituitary based on in situ hybridization and immunohistochemistry studies (25, 26). Folliculostellate cells form a network for long-distance communication in the anterior pituitary (27) but their exact role is not clear. Based on the present identification of $\mathrm{A} 2$ and $\mathrm{B} 5$ expression in the anterior pituitary, thyrostimulin could be part of an ultra-short loop in the fine-tuning of TSH secretion. Future studies on the regulatory mechanisms underlying the expression of pituitary A2 and B5 genes are important. Because extra-thyroid expression of the TSH receptor has also been demonstrated in brain (28), orbital fibroblasts (29), heart (29), thymus (30), and adipose tissues $(31,32)$, studies on the production of thyros- timulin by these extra-thyroid tissues are of interest. The exact physiological role of thyrostimulin could be revealed by studying animals with a targeted mutation of A2 or B5 genes, as well as the identification of patients with defects in these genes.

Recombinant human TSH has been used to facilitate the monitoring for thyroid carcinoma (33). Because the A2/B5 heterodimer showed potent TSHlike bioactivity in vivo, the availability of recombinant thyrostimulin provides an additional diagnostic tool for thyroid tumors.

Demonstration of the TSH receptor-stimulating activity of the thyrostimulin heterodimer provides an understanding of the structural-functional relationship of different $\alpha$ and $\beta$ subunits in the glycoprotein hormone family. The known glycoprotein hormone heterodimers are believed to be stabilized by a segment of the $\beta$ subunit, which wraps around the $\alpha$ subunit like a seat belt (8). However, the B5 subunit is unique in that it lacks the disulfide bond important for seat belt formation. Indeed, the present analysis indicated that the A2/B5 heterodimer is less stable than the known glycoprotein hormones during SDS-PAGE analysis. Although the lower affinity between A2 and B5 subunits precludes its purification using procedures similar to those for classic glycoprotein hormones, the recombinant heterodimer could be detected using the present approaches based on dimer purification and cross-linking analyses, underlining the value of this paradigm in identifying the remaining members of the glycoprotein hormone family.

Substitution of the seat belt region of TSH- $\beta$ with the corresponding regions of CG- $\beta$ or FSH- $\beta$ confers LH but not FSH activity to chimeric TSH (34), whereas a point mutation of the key cysteine 105 in TSH- $\beta$ near the seat belt region led to the formation of inactive circulating TSH (22). Because the seat belt conformation does not seem to play a prominent role in the bioactivity of FSH (35), structural-functional studies using B5 are of interest and could reveal the exact domains involved in the specificity of receptor interactions for ligands of this family. Among different glycoprotein hormones, the crystal structure for hCG and FSH has been elucidated $(8,36)$. The thyrostimulin heterodimer provides a unique model for further elucidation of the structural-functional relationship of this family of cystine knot-containing glycoprotein ligands.

It has been proposed that the $\beta$ subunits of gonadotropins and TSH provide the specificity for receptor interactions, whereas the common $\alpha$ subunit interacts with the transmembrane region of the receptor to activate $G$ proteins (37). The present finding of TSH receptor activation by A2/B5 suggests that B5 may be responsible for the interaction with the ectodomain of the TSH receptor, whereas A2 activates the transmembrane region of the occupied receptor. However, our preliminary testing indicated that a heterodimer consisting of the known $\alpha$ and new B5 subunits did not activate the TSH receptor, and the A2/CG- $\beta$ heterodimer did not 
activate the $\mathrm{LH}$ receptor. Thus, different heterodimers, including A2/B5, likely assume a distinct conformation in the heterodimeric state that is optimal for interaction with specific receptors. Gene fusion and domain swapping among different glycoprotein hormone subunit genes have been applied to generate diverse recombinant gonadotropin and thyrotropin analogs $(9,38,39)$. Similar approaches using A2 and B5 subunits could facilitate understanding of ligand signaling mechanisms for hormones in this family.

In conclusion, the present study provides a new approach for discovering heterodimeric protein hormones based on the phylogenetic relationships among paralogous genes and the use of yeast two-hybrid analysis to identify heterodimeric ligand candidates. Although the yeast assay has been used extensively to test potential interactions between pairs of intracellular proteins (12), its utility for extracellular proteins has been limited (40). The discovery of a new functional heterodimeric hormone in the glycoprotein hormone family paves the way for the identification of the remaining members of this ligand family and future elucidation of the evolutionary relationship between this family of heterodimeric ligands, the known glycoprotein hormone receptors, and the related leucine-rich, repeat-containing, $G$ protein-coupled receptors $(41,42)$.

\section{Acknowledgments}

This work was supported by NIH grant HD-23273. We thank Danette Daniels and T. Sugawara of Stanford University for help in the purification of thyrostimulin and immunostaining, C. Spencer for editorial assistance, G. Vassart (Free University, Belgium) for TSH receptor cDNA, and the National Hormone \& Peptide Program for different pituitary hormones.

1. Greep, R.O., Fevold, H.L., and Hisaw, F.L. 1936. Effects of two hypophyseal gonadotropic hormones on the reproductive system of the male rat. Anat. Record. 65:261-271.

2. Simpson, M.E., Evans, H.M., and Li, C.H. 1950. Effect of pure FSH alone or in combination with chorionic gonadotropin in hypophysectomized rats of either sex. Anat. Record. 106:247-248.

3. Pierce, J.G., Liao, T., Howard, S.M., Shome, B., and Cornell, J.S. 1971. Studies on the structure of thyrotropin: its relationship to luteinizing hormone. Recent Prog. Horm. Res. 27:165-212.

4. Shupnik, M.A., Ridgway, E.C., and Chin, W.W. 1989. Molecular biology of thyrotropin. Endocr. Rev. 10:459-475.

5. Weetman, A.P. 2000. Graves' disease. N. Engl. J. Med. 343:1236-1248.

6. Paschke, R., and Ludgate, M. 1997. The thyrotropin receptor in thyroid diseases. N. Engl. J. Med. 337:1675-1681.

7. Hsu, S.Y., Nakabayashi, K., and Bhalla, A. 2002. Evolution of glycoprotein hormone subunit genes in bilateria: identification of two novel human glycoprotein hormone subunit family genes, GPA2 and GPB5. Mol. Endo. In press.

8. Lapthorn, A.J., et al. 1994. Crystal structure of human chorionic gonadotropin. Nature. 369:455-461.

9. Weintraub, B.D., and Szkudlinski, M.W. 1999. Development and in vitro characterization of human recombinant thyrotropin. Thyroid. 9:447-450.

10. Vitt, U.A., Hsu, S.Y., and Hsueh, A.J. 2001. Evolution and classification of cystine knot-containing hormones and related extracellular signaling molecules. Mol. Endocrinol. 15:681-694.

11. Isaacs, N.W. 1995. Cystine knots. Curr. Opin. Struct. Biol. 5:391-395.

12. Fields, S., and Song, O. 1989. A novel genetic system to detect protein-protein interactions. Nature. 340:245-246.

13. Hsu, S.Y., Kaipia, A., McGee, E., Lomeli, M., and Hsueh, A.J. 1997. Bok is a pro-apoptotic $\mathrm{Bcl}-2$ protein with restricted expression in reproductive tissues and heterodimerizes with selective anti-apoptotic Bcl-2 family members. Proc. Natl. Acad. Sci. USA. 94:12401-12406.
14. Hsu, S.Y. 1999. Cloning of two novel mammalian paralogs of relaxin/insulin family proteins and their expression in testis and kidney. Mol. Endocrinol. 13:2163-2174.

15. Sugawara, T., Fujimura, M., Morita-Fujimura, Y., Kawase, M., and Chan, P.H. 1999. Mitochondrial release of cytochrome $c$ corresponds to the selective vulnerability of hippocampal CA1 neurons in rats after transient global cerebral ischemia. J. Neurosci. 19:RC39.

16. Nakabayashi, K., Kudo, M., Kobilka, B., and Hsueh, A.J. 2000. Activation of the luteinizing hormone receptor following substitution of Ser-277 with selective hydrophobic residues in the ectodomain hinge region. J. Biol. Chem. 275:30264-30271.

17. Parmentier, M., et al. 1989. Molecular cloning of the thyrotropin receptor. Science. 246:1620-1622.

18. Kudo, M., Osuga, Y., Kobilka, B.K., and Hsueh, A.J. 1996. Transmembrane regions $\mathrm{V}$ and $\mathrm{VI}$ of the human luteinizing hormone receptor are required for constitutive activation by a mutation in the third intracellular loop. J. Biol. Chem. 271:22470-22478.

19. Jin, S., Hornicek, F.J., Neylan, D., Zakarija, M., and McKenzie, J.M. 1986. Evidence that adenosine $3^{\prime}, 5^{\prime}$-monophosphate mediates stimulation of thyroid growth in FRTL5 cells. Endocrinology. 119:802-810.

20. East-Palmer, J., Szkudlinski, M.W., Lee, J., Thotakura, N.R., and Weintraub, B.D. 1995. A novel, nonradioactive in vivo bioassay of thyrotropin (TSH). Thyroid. 5:55-59.

21. Faglia, G., et al. 1979. Thyrotropin secretion in patients with central hypothyroidism: evidence for reduced biological activity of immunoreactive thyrotropin. J. Clin. Endocrinol. Metab. 48:989-998.

22. Medeiros-Neto, G., et al. 1996. A circulating, biologically inactive thyrotropin caused by a mutation in the beta subunit gene. J. Clin. Invest. 97:1250-1256.

23. Heinrichs, C., et al. 2000. Congenital central isolated hypothyroidism caused by a homozygous mutation in the TSH-beta subunit gene. Thyroid. 10:387-391.

24. Miyai, K., Azukizawa, M., and Kumahara, Y. 1971. Familial isolated thyrotropin deficiency with cretinism. N. Engl. J. Med. 285:1043-1048.

25. Prummel, M.F., et al. 2000. Expression of the thyroid-stimulating hormone receptor in the folliculo-stellate cells of the human anterior pituitary.J. Clin. Endocrinol. Metab. 85:4347-4353.

26. Theodoropoulou, M., et al. 2000. Thyrotrophin receptor protein expression in normal and adenomatous human pituitary. J. Endocrinol. 167:7-13.

27. Fauquier, T., Guerineau, N.C., McKinney, R.A., Bauer, K., and Mollard, P. 2001. Folliculostellate cell network: a route for long-distance communication in the anterior pituitary. Proc. Natl. Acad. Sci. USA. 98:8891-8896.

28. Crisanti, P., et al. 2001. The expression of thyrotropin receptor in the brain. Endocrinology. 142:812-822.

29. Bell, A., et al. 2000. Functional TSH receptor in human abdominal preadipocytes and orbital fibroblasts. Am. J. Physiol. Cell Physiol. 279:C335-C340.

30. Spitzweg, C., Joba, W., and Heufelder, A.E. 1999. Expression of thyroidrelated genes in human thymus. Thyroid. 9:133-141.

31. Birnbaumer, L., and Rodbell, M. 1969. Adenyl cyclase in fat cells. II. Hormone receptors. J. Biol. Chem. 244:3477-3482.

32. Roselli-Rehfuss, L., Robbins, L.S., and Cone, R.D. 1992. Thyrotropin receptor messenger ribonucleic acid is expressed in most brown and white adipose tissues in the guinea pig. Endocrinology. 130:1857-1861.

33. Haugen, B.R., et al. 1999. A comparison of recombinant human thyrotropin and thyroid hormone withdrawal for the detection of thyroid remnant or cancer. J. Clin. Endocrinol. Metab. 84:3877-3885.

34. Grossmann, M., et al. 1997. Substitution of the seat-belt region of the thyroid-stimulating hormone (TSH) beta-subunit with the corresponding regions of choriogonadotropin or follitropin confers luteotropic but not follitropic activity to chimeric TSH. J. Biol. Chem. 272:15532-15540.

35. Hiro'oka, T., Maassen, D., Berger, P., and Boime, I. 2000. Disulfide bond mutations in follicle-stimulating hormone result in uncoupling of biological activity from intracellular behavior. Endocrinology. 141:4751-4756.

36. Fox, K.M., Dias, J.A., and Van Roey, P. 2001. Three-dimensional structure of human follicle-stimulating hormone. Mol. Endocrinol. 15:378-389.

37. Ji, T.H., Ryu, K.S., Gilchrist, R., and Ji, I. 1997. Interaction, signal generation, signal divergence, and signal transduction of LH/CG and the receptor. Recent Prog. Horm. Res. 52:431-453.

38. Garcia-Campayo, V., and Boime, I. 2001. Novel recombinant gonadotropins. Trends Endocrinol. Metab. 12:72-77.

39. Puett, D., Wu, C., and Narayan, P. 1998. The tie that binds: design of biologically active single-chain human chorionic gonadotropins and a gonadotropin-receptor complex using protein engineering. Biol. Reprod. 58:1337-1342.

40. Legrain, P., and Selig, L. 2000. Genome-wide protein interaction maps using two-hybrid systems. FEBS Lett. 480:32-36.

41. Hsu, S.Y., et al. 2000. The three subfamilies of leucine-rich repeat-containing $G$ protein-coupled receptors (LGR): identification of LGR6 and LGR7 and the signaling mechanism for LGR7. Mol. Endocrinol. 14:1257-1271.

42. Hsu, S.Y., et al. 2002. Activation of orphan receptors by the hormone relaxin. Science. 295:672-674. 